\title{
Spatial Network Structures of Urban Agglomeration Based on the Improved Gravity Model: A Case Study in China's Two Urban Agglomerations
}

\author{
Yubo Zhao $\mathbb{D}^{1}{ }^{1}$ Gui Zhang ${ }^{(D)}{ }^{2}$ and Hongwei Zhao' \\ ${ }^{1}$ School of Economics and Management, Hebei University of Technology, Tianjin 300401, China \\ ${ }^{2}$ College of Economic and Social Development, Nankai University, Tianjin 300701, China \\ Correspondence should be addressed to Gui Zhang; zhanggui2050@126.com
}

Received 8 November 2020; Revised 17 January 2021; Accepted 25 January 2021; Published 8 February 2021

Academic Editor: Anirban Chakraborti

Copyright (c) 2021 Yubo Zhao et al. This is an open access article distributed under the Creative Commons Attribution License, which permits unrestricted use, distribution, and reproduction in any medium, provided the original work is properly cited.

Research on urban agglomerations from the perspective of network spatial structure is important to promote their sustainable development. Based on online and traditional data, this paper first improves three aspects of the traditional spatial gravity model-city quality, the gravitation coefficient, and city distance-considering urban center functional intensity and population mobility tendencies. The resulting improved directional gravity model is applied to analyze the structure of the city network for two urban agglomerations in China, the Beijing-Tianjin-Hebei urban agglomeration (BTHUA) and the Yangtze River Delta urban agglomeration (YRDUA). The results of the study are as follows: (1) the existing urban connections have obvious hierarchies and imbalances, with the YRDUA urban hierarchical connections being of larger scale. (2) Cities are closely connected, but city networks are unbalanced, though the YRDUA has more balanced urban development. (3) Each node city has a clear radiation range limit, and spatial distance remains an important constraint on urban connections. The backbone network of the BTHUA has a triangular shape and trends toward a "sparse north and dense south," while the YRDUA is characterized by multiple axes and an overall distribution that trends toward a "dense north and sparse south." (4) Cities with poor comprehensive strength are more likely to be captured, forming an attract and be attracted relationship. (5) The BTHUA and the YRDUA each form three communities.

\section{Introduction}

As a relatively complete aggregate and a basic regional unit that participates in global competition and the international division of labor, the development of urban agglomerations not only affects a country's international competitiveness but also has great significance for the sustained and stable development of a country and its regional economies [1]. With the continuous acceleration of industrialization and urbanization and the coordinated development of regional economies, urban agglomerations have gradually become the main spatial form promoting China's new urbanization. The coordinated development of China's core hub cities and surrounding areas has become an important form for promoting new urbanization. To improve the quality of urbanization development and promote the benign and sustainable future development of urban agglomerations, it is particularly necessary to explore and study the evolution of urban agglomerations from the perspective of spatial structure [2]. As the main manifestation and material carrier of urban agglomeration and urbanization development, the spatial structure of urban agglomerations can reflect not only the interaction and relationship between cities within the urban agglomeration but also the development stage and level of the urban agglomeration. The research on the spatial structure of urban agglomerations mainly distinguishes and optimizes the degree, stage, and process of urban agglomeration development from a spatial perspective [3].

With the acceleration of the globalization process and the increasingly close connections between cities, space for 
flows has gradually replaced space for places as the basic theory of urban agglomeration space research [4]. Similarly, Castells pointed out that innovations in communication and information technology have transformed the dominant spatial form from the space of places into the space of flows, which forms a network organization that has become an important structural element of the global social economic system [5]. As an important manifestation of the spatial structure of urban agglomerations, network structure not only reflects the combination of points and lines between cities and towns but also expands the static structure of central place theory, such as the hierarchy, order, and scale of the space of flows. This system can better reflect various structural systems based on transportation and administrative and market elements within its spatial scope. Based on the space of flows theory, Camagni [6] first proposed the "city network" paradigm to explain the emerging urban spatial structure. In the past, city network spatial structure research mainly used traffic flow and enterprise organization flow to describe city networks.

Existing related research in the field of traffic flow mainly focuses on three aspects: air passenger flow [7-9], highspeed rail passenger flow [10-12], and intercity railway passenger flow [13]. Additional studies describe and compare the correlation characteristics of city networks by comprehensively diversifying passenger traffic flows [14, 15].

Regarding the corporate organization flow, Taylor was the first to establish a city chain network based on the connections between companies between cities, using network analysis methods to reveal the status of cities in the network [16]. On the basis of Taylor's research, some scholars have carried out extensive research on the organizational structure of city networks through the association of corporate headquarters and branches and have achieved rich results [17-21]. Corresponding to the city network constructed from the internal organizational structure of enterprises, other scholars have considered the high research value of interfirm linkages and used microindustry chain surveys, venture capital investments, and enterprise initial public offerings to carry out relevant city network research. These studies further improve city network research based on enterprise organization flows $[22,23]$.

The above studies are mostly based on statistical data. Although authoritative and reliable, they often have disadvantages such as a time lag or inconsistent statistical quality. With the development of information and communication technology, the network connection between cities is no longer limited to traditional aspects such as transportation, trade, and population flow. Research on city networks as represented by information flow has begun to attract scholarly attention. These scholars use web page hyperlinks [24], the Baidu Index [25], Baidu Tieba [26], Sina Weibo [27], and other Internet information data to study city networks. In summary, the information flow between cities as identified by Internet technology is a new alternative method for measuring and characterizing urban connections, and it is also an effective supplement to existing city network research data sources. Using Internet data to characterize the strength of the information connections between cities and simulate the city network can reflect changes in that network more accurately and dynamically and in real time. However, the city network is different from a single social network or enterprise network; it is diverse and integrated, covers economic, social, environmental, and other aspects, and has its own organizational methods and dynamic characteristics [28]. An approach is urgently needed that can more realistically describe the network space of urban agglomerations. Previous studies have considered the diversity and integration of city networks, and city networks have been constructed through improved gravity models [29-31]. However, most studies have analyzed city networks from an undirected perspective, ignoring the asymmetrical flow of elements in city networks.

In addition, different urban agglomerations have different development processes, industrial foundations, and resource endowments, and the development status of urban agglomerations also presents contrasts. The practical guiding significance of comparative research on urban agglomerations with large development differences is limited. The Beijing-Tianjin-Hebei urban agglomeration (BTHUA) and the Yangtze River Delta urban agglomeration (YRDUA) are two important urban agglomerations in China. On the one hand, these two urban agglomerations have implemented a national strategy of coordinated and integrated development. These urban agglomerations have gathered multiple national comprehensive scientific research centers, universities, scientific research institutions, and innovative enterprises, and they are characterized by dense high-level talent and domestically leading innovation capabilities and levels. On the other hand, these two major urban agglomerations have similar geographic areas and span different administrative regions, their industrialization process is relatively advanced, and their development stages are relatively similar. Therefore, this paper chooses the BTHUA and the YRDUA as the research objects. A comparative analysis of the spatial structure of the two major urban agglomerations in the BTHUA and the YRDUA is of great significance, as it can help promote the coordinated regional development of China and narrow the development gap between China's north and south.

The innovation of this paper is mainly reflected in the following three aspects: (1) most previous studies have improved urban spatial gravity models from a single aspect of city quality, city distance, or gravitational coefficients, and most constructed gravity models are not directional. Traditional urban spatial gravity models use indicators such as population and GDP to characterize urban quality [32], but, with the progress of society and people's demands from urban life, the quality of cities is reflected not only in their economy but also in their urban environment, residents' lives, and social security. Therefore, this paper constructs a city center function evaluation index system, uses principal component analysis to extract the six main components, and uses a city center function intensity model to calculate the city quality to fully reflect the city quality level. For city distance, existing studies mostly use geographic distance, which is calculated by the straight-line distance between two cities or the sum of road and railway mileage [29]. However, 
with the development of transportation technology, economic and trade activities focus on the time and currency cost of the journey between cities. Therefore, this paper uses economic distance considering time cost and currency cost to characterize urban distance, as this is more in line with the actual development of intercity links. Regarding the gravitational coefficient, most studies adopt the default value of 1 [31] or construct the gravitational coefficient according to the proportion of economic indicators between cities $[30,33]$, such as the ratio of urbanization rate [34] or GDP [35] of between cities. But the premise of the gravitational coefficient constructed by this processing method is to assume that the higher the level of urban development, the more attractive the city, which is not the real connection between cities and cannot reflect the real-world interaction between cities. As the most active element in the interaction of elements between cities, population flow is a comprehensive reflection of element flow. The gravitational coefficient constructed based on the population flow between cities can better reflect the full picture of the real interactions between cities. Therefore, this paper constructs a population mobility tendency model to improve the gravitational coefficient, making it a vector variable that can better reflect the interaction between cities. Based on the above analysis, this paper finally constructs a directional gravity model that offers an improved ability of explaining the networks underlying urban agglomerations and provides a new research concept for studying the network space of urban agglomerations. (2) Multisource heterogeneous data are an important standard for future empirical analysis of data source requirements. This paper integrates traditional statistical data and Internet data to ensure authoritative, reliable, and dynamically accurate data. The combined use of two kinds of data means that they can support and confirm each other. (3) Previous studies have examined the spatial structure of individual urban agglomerations in the BTHUA and the YRDUA, but few have analyzed the similarities and differences between the two from a comparative perspective. This paper starts with a comparative perspective, uses social network methods to analyze the similarities and differences in the spatial structure of the BTHUA and YRDUA, and further deepens understanding of their development.

Through the above marginal contributions, we hope to describe the urban agglomeration network more truly and accurately. Building upon an accurate characterization of the city network, we further use social networks and other methods to describe and compare the spatial structure of China's two urban agglomerations.

\section{Materials and Methodologies}

2.1. Research Area. The BTHUA and YRDUA, as China's two major urban agglomerations, are China's important regional growth poles. The BTHUA covers an area of 217,158 square kilometers and is the largest urban agglomeration in northern China. It includes two municipalities directly under the central government of Beijing and Tianjin and 11 prefecture-level cities in Hebei Province, totaling 13 cities. Among them, Beijing and Tianjin, as municipalities directly under the central government, have always held an advantage in the field of economic development, and their economic aggregates are in the first echelon of domestic cities. The YRDUA is located on the alluvial plain at the mouth of the Yangtze River and is one of the most active, open, and innovative regions in China. According to the "Outline of the Yangtze River Delta Regional Integration Development Plan" promulgated by the State Council of China, the YRDUA covers the entire region of Shanghai, Jiangsu, Zhejiang, and Anhui, with a total of 27 cities. Among them, Jiangsu Province includes 9 cities: Nanjing, Wuxi, Changzhou, Suzhou, Nantong, Yangzhou, Zhenjiang, Yancheng, and Taizhou. Zhejiang Province also includes 9 cities: Hangzhou, Ningbo, Wenzhou, Huzhou, Jiaxing, Shaoxing, Jinhua, Zhoushan, and Taizhou. Anhui Province includes 8 cities: Hefei, Wuhu, Ma'anshan, Tongling, Anqing, Chuzhou, Chizhou, and Xuancheng. Among them, the municipality of Shanghai is directly under the central government and is China's international economic and trade, financial, and technological innovation center. Nanjing, Hangzhou, and Hefei are the capital cities of Jiangsu, Zhejiang, and Anhui, respectively. The geographic locations of the BTHUA and YRDUA are shown in Figure 1.

2.2. Data Sources. The data on urban centrality indicators mainly come from the China City Statistical Yearbook (2018), with some taken from the Beijing Statistical Yearbook (2018), Tianjin Statistical Yearbook (2018), Hebei Economic Yearbook (2018), Jiangsu Statistical Yearbook (2018), Zhejiang Statistical Yearbook (2018), and Anhui Statistical Yearbook (2018).

Second, urban highway mileage comes from the National Highway Network Atlas (2018), China Highway and Urban and Rural Highway Network Atlas (2018), China Highway Network Quick Survey Atlas (2018), and Hebei and surrounding provinces and regions highway Net Atlas (2018). Some of the missing data were obtained using the shortest road mileage shown in Baidu Maps. Based on People's Republic of China Highway Engineering Technical Standards, the road speed is set to $80 \mathrm{~km} / \mathrm{h}$. The time spent traveling by road is calculated from the road mileage and driving speed. The data on the monetary cost of highways are taken from the bus ticket query network (http://www.checi. org) and the Tieyou ticket query network (http://qiche. tieyou.com). Railway time cost data and currency cost data are from the China Railway Customer Service Center website (https://www.12306.cn/). For cities lacking direct trains, the train with the shortest transfer time is used as supplementary data.

Finally, the data on population mobility tendency come from the Baidu Index data platform. The data collection website is http://index.baidu.com. The data collection period is from January 1, 2017, to December 31, 2017.

\subsection{Research Methods}

2.3.1. Improved Gravity Model. The gravity model is commonly used for the study of urban connections in a region. It 


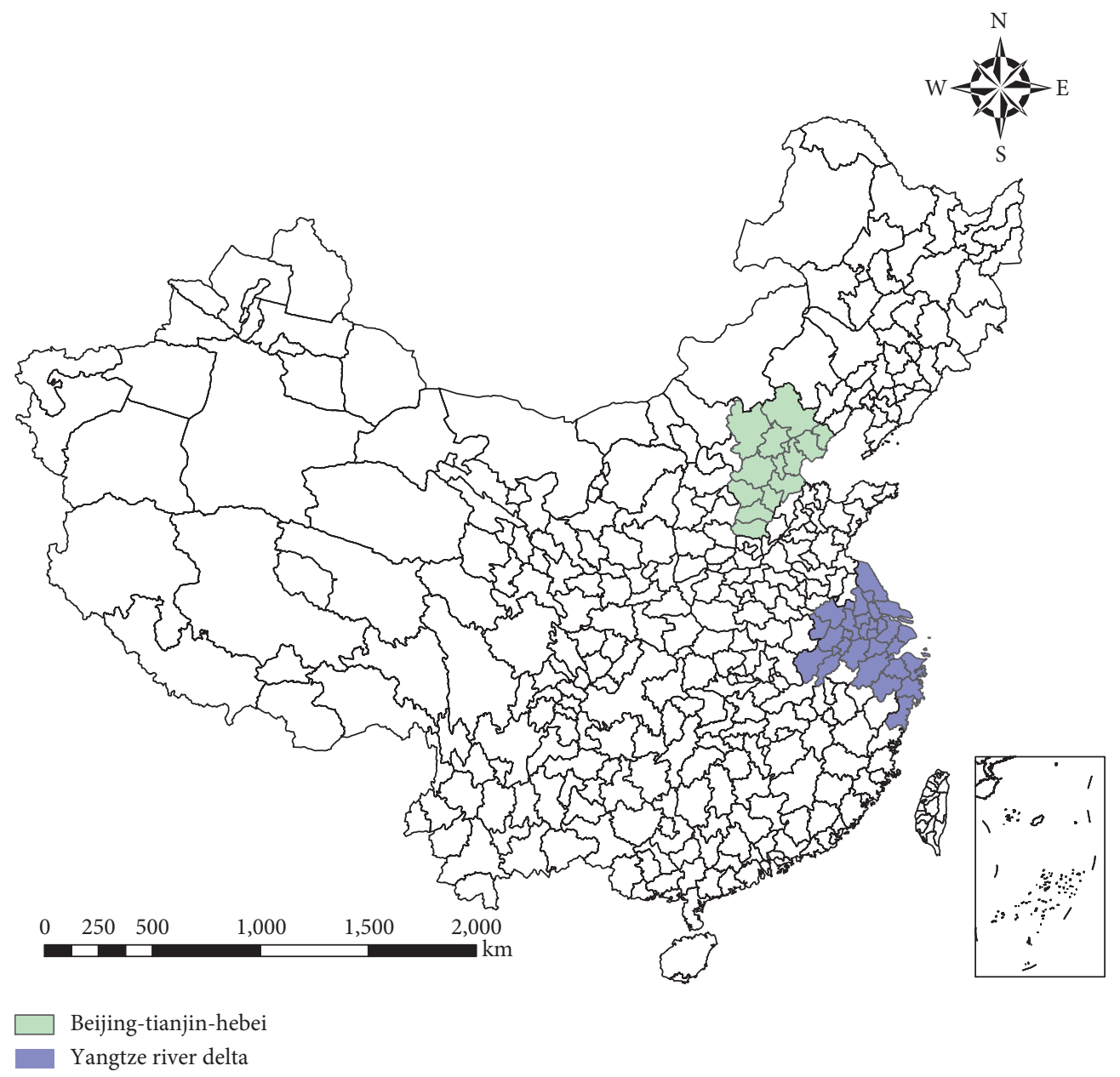

FIgURe 1: Location of the BTHUA and YRDUA in China.

is simple and easy to use, making it widely used in regional trade, resource flow, and urban space research. The calculation of the gravity model is shown as follows:

$$
\operatorname{Link}_{i j}=g \times \frac{M_{i} M_{j}}{D_{i j}^{2}},
$$

where $\operatorname{Link}_{i j}$ is the connection degree between city $i$ and city $j ; g$ is the gravitational coefficient, which is a constant; $M_{i}$ and $M_{j}$ are the quality indicators of cities $i$ and $j$, respectively; and $D_{i j}$ is the distance between city $i$ and city $j$.

First, the city quality parameters are improved. China's urban development is characterized by the unbalanced development of urban functions, and a single indicator such as population and regional GDP cannot represent the diversity or the integration of city network connections. The functional intensity model of the city center was proposed by the German economic geographer W. Christaller, and it is an important indicator for measuring the status of a city's functions [36]. The model uses multiple indicators that reflect the central functions of the city, including the economy, the population, investments, and consumption, to calculate a central function intensity index and thereby reflect the comprehensive strength and external influence of the city. Based on previous studies in [29-32, 37-39], this paper establishes a city center function evaluation index system with 38 indicators (as shown in Table 1) considering the aspects of population size, economic aggregation, and residents' quality of life. Using principal components analysis, six principal components are extracted, and the principal component scores of each index are substituted into the city center function intensity model (as shown in formula (2)) to obtain the center function intensity index of each city to more accurately and comprehensively characterize that city's quality.where $K_{i}$ is the central functional intensity index of city $i$; $K_{\mathrm{Pop}_{i}}, K_{\mathrm{Eco}_{i}}, K_{\mathrm{Soc}_{i}}, K_{\mathrm{Econ}_{i}}, K_{\mathrm{Tra}_{i}}$, and $K_{\text {Inf }_{i}}$ are the central function indexes of population, ecology, society, economy, transportation, and infrastructure of city $i$, respectively. $K_{\mathrm{Pop}_{i}}=\operatorname{Pop}_{i} /\left((1 / n) \sum_{i=1}^{n} \operatorname{Pop}_{i}\right)$, where $\mathrm{Pop}_{i}$ is the population principal component score of city $i$, and $n$ is the number of sample cities; the other five central function indexes can be obtained in the same way. The calculations of principal component score can be found in [40].

$$
K_{i}=\frac{K_{\mathrm{Pop}_{i}}+K_{\mathrm{Eco}_{i}}+K_{\mathrm{Soc}_{i}}+K_{\mathrm{Econ}_{i}}+K_{\mathrm{Tra}_{i}}+K_{\mathrm{Inf}_{i}}}{6},
$$

Second, the city distance parameter is improved. Previous studies mostly used geographic distance to 
TABLE 1: Urban agglomeration centrality evaluation index system.

\begin{tabular}{|c|c|c|c|}
\hline Subsystem & Indicators & Unit & Reference \\
\hline Population size & $\begin{array}{c}\text { Total population } \\
\text { Natural population growth rate }\end{array}$ & $\begin{array}{c}\text { Ten thousand } \\
\%\end{array}$ & {$[32,38,39]$} \\
\hline Economic aggregate and structure & $\begin{array}{c}\text { GDP } \\
\text { Industrial output value above designated size } \\
\text { Investment in fixed assets } \\
\text { Public revenue } \\
\text { Proportion of tertiary industry }\end{array}$ & $\begin{array}{c}\text { Ten thousand yuan } \\
\text { Ten thousand yuan } \\
\text { Ten thousand yuan } \\
\text { Ten thousand yuan } \\
\%\end{array}$ & [37-39] \\
\hline $\begin{array}{l}\text { Economic benefits and foreign } \\
\text { investment }\end{array}$ & $\begin{array}{c}\text { GDP growth rate } \\
\text { GDP per capita } \\
\text { Per capita financial income } \\
\text { Actually utilized foreign capital in that year }\end{array}$ & $\begin{array}{c}\% \\
\text { Yuan } \\
\text { Yuan/person } \\
\text { Ten thousand US } \\
\text { dollars }\end{array}$ & {$[30,31]$} \\
\hline Resident life & $\begin{array}{c}\text { The total retail sales of social consumer goods } \\
\text { Public expenditure } \\
\text { Average wage of urban employees } \\
\text { Deposit balance per capita of financial institutions } \\
\text { Per capita disposable income of urban residents } \\
\text { Number of people participating in basic pension insurance for } \\
\text { urban employees }\end{array}$ & $\begin{array}{l}\text { Ten thousand yuan } \\
\text { Ten thousand yuan } \\
\text { Yuan } \\
\text { Yuan } \\
\text { Yuan } \\
\text { Person }\end{array}$ & {$[29,30]$} \\
\hline $\begin{array}{l}\text { Science, education, culture, and } \\
\text { health services }\end{array}$ & $\begin{array}{c}\text { Number of ordinary college students per } 10,000 \text { people } \\
\text { Education expenditure } \\
\text { Number of full-time teachers in ordinary universities } \\
\text { Number of hospital beds } \\
\text { Doctors per } 10,000 \text { people } \\
\text { Library collection per capita } \\
\text { Patent application authorization }\end{array}$ & $\begin{array}{l}\text { Person } \\
\text { Ten thousand yuan } \\
\text { Person } \\
\text { Bed } \\
\text { Person } \\
\text { Volumes } \\
\text { Item } \\
\end{array}$ & {$[29,31]$} \\
\hline Traffic communication & $\begin{array}{c}\text { Urban road area per capita } \\
\text { Total post and telecommunication services } \\
\text { Number of mobile phone users at the end of the year } \\
\text { Number of Internet broadband users } \\
\text { Number of bus operations } \\
\text { Highway mileage }\end{array}$ & $\begin{array}{l}\text { Square meter } \\
\text { Ten thousand yuan } \\
\text { Ten thousand } \\
\text { households } \\
\text { Ten thousand } \\
\text { households } \\
\text { Vehicle } \\
\text { Kilometers } \\
\end{array}$ & {$[29-31]$} \\
\hline Infrastructure & $\begin{array}{c}\text { Built-up areas } \\
\text { Drainage pipe density } \\
\text { Water consumption per capita } \\
\text { Road freight } \\
\text { Highway passenger traffic }\end{array}$ & $\begin{array}{l}\text { Square kilometers } \\
\mathrm{M} / \mathrm{m}^{2} \\
\text { Ton } \\
\text { Ten thousand tons } \\
\text { Ten thousand } \\
\text { persons }\end{array}$ & {$[29,39]$} \\
\hline Waste disposal & Sewage treatment rate & $\%$ & {$[29,39]$} \\
\hline Urban afforestation & $\begin{array}{c}\text { Green coverage } \\
\text { Per capita public green area }\end{array}$ & $\begin{array}{c}\% \\
\text { Square meter }\end{array}$ & {$[29,31]$} \\
\hline
\end{tabular}

characterize the distance between cities. With the development of transportation technology, it is obvious that considering the economic distance between time cost and currency cost is more in line with the actual development of intercity links. Therefore, this study uses economic distance to characterize the distance between cities. In addition, because road and railway are the main modes of transportation in China [41], only these two modes of transportation are considered in the calculation of distance parameter as shown in the following equation:

$$
D_{i j}=\sqrt{\left(\cos 1_{i j} \operatorname{Tim} 1_{i j}\right)\left(\cos 2_{i j} \operatorname{Tim} 2_{i j}\right)},
$$

where $\cos 1_{i j}$ represents the monetary cost of road travel between city $i$ and city $j$ and $\operatorname{Tim} 1_{i j}$ represents the road travel time between cities $i$ and $j$. cos $2_{i j}$ represents the currency cost of rail travel between cities $i$ and $j$, and $\operatorname{Tim} 2_{i j}$ represents the rail travel time between cities $i$ and $j . D_{i j}$ represents the comprehensive distance between cities $i$ and $j$.

Third, the gravitational coefficient parameter is improved. Most scholars' improvements to the gravity model are only reflected in the city quality and the distance between cities, and there are few studies improving the gravity coefficient. In those that do exist, most of the improvements are made from the perspective of economic development. 
The population flow carries many dimensions of connection, and it can represent the flow and connection between economic, social, cultural, and other elements in the city network. There is a close connection between population movement and urban development. The agglomeration and departure of the population also to some extent reflect the degree to which the spatial structure of the urban agglomeration is rationalized and its level of development.

Baidu is the world's largest Chinese search engine and the search engine most used by Chinese netizens. According to the Statistical Report on China's Internet Development Status (July 2017) released by the China Internet Network Information Center and statistics from StatCounter, Baidu Search has a brand penetration rate of $93.10 \%$ among China's 609 million search engine users. Therefore, a proxy variable for population mobility tendency constructed using the Baidu Index has good representativeness. The Baidu Index is based on the search behavior of the majority of netizens on Baidu, using keyword search volume as the main statistical indicator to obtain netizens' attention data. Attention is an individual's search behavior based on interest and willingness [42], and it can objectively depict people's economic and social behavior characteristics on a time axis [43]. Searching for specific keywords can to some extent reflect the psychological demand of Internet users and is of great significance for predicting the behavior of Internet users.

The process for processing the population mobility variable is as follows:

(1) Select search keywords. With the popularity of online search engines, an increasing number of individual economic and social behaviors are reflected in individual online search behaviors [44-46]. The tendency toward population mobility refers to the psychological willingness of people to move from one area to another as it exists in their psychological cognition. Based on the accessibility and timeliness of the data acquired on big data platforms through web searches, scholars [47-49] often use data platforms such as the Baidu Index to obtain user mobility data to characterize and predict population mobility. According to push-pull theory [50] and the research results of Xu et al. [51], population flows to a certain area mainly to achieve higher income levels and lower living costs $[52,53]$. In China currently, the biggest impact on the cost of living is housing prices and the rent levels within the inflow area [54]. Therefore, this paper first conducts exploratory keyword selection. According to the rule of least effort in information retrieval behavior [55], the keywords related to income level are initially selected as "salary," "income," "salary level," "Income level," "per capita income," "recruitment," and "work," among others. In terms of house prices and rents, the keywords are initially selected as "house price," "rental house," "rental," "real estate," and "house." Then, a correlation analysis was conducted between the keyword search volume and the sample data of the China Migrants Dynamic Survey, which determined that "recruitment + work" is the key term to capture flows related to the city's income levels, and "house price + rent" is the key term to capture flows related to the city's housing prices and rent levels. In addition, based on the characteristics of short-term population mobility (such as tourism and business trips), "weather" and "map" are selected as supplementary keywords for population mobility trends [56-58].

(2) The data variables for population mobility tendency are constructed. Define $X_{i j}$ as the tendency in population flow from city $i$ to city $j$; the calculation formula is shown in the following equation:

$$
X_{i j}=\sqrt[4]{\operatorname{Hou}_{i j} \times \mathrm{Job}_{i j} \times \mathrm{Wea}_{i j} \times \mathrm{Map}_{i j}}, \quad(i \neq j),
$$

where $\mathrm{Hou}_{i j}$ is the search index of Internet users in city $i$ for the keyword "housing + rent" in city $j, J \mathrm{Job}_{i j}$ is the search index of Internet users in city $i$ for the keyword "recruitment + work" in city $j, \mathrm{Wea}_{i j}$ is the search index of Internet users in city $i$ for the keyword "weather" in city $j$, and $\mathrm{Map}_{i j}$ is the search index of Internet users in city $i$ for the keyword "map" in city $j$.

Define $X_{j i}$ as the tendency in population flows from city $j$ to city $i$. The calculation formula can be obtained as follows:

$$
X_{j i}=\sqrt[4]{\operatorname{Hou}_{j i} \times \mathrm{Job}_{j i} \times \mathrm{Wea}_{j i} \times \operatorname{Map}_{j i}}, \quad(j \neq i) .
$$

Finally, this paper uses the function strength of the city center to characterize the quality of the city and the tendency of population mobility to characterize the direction of urban gravity. The gravity model is thereby improved, and a directed gravity model is constructed to improve the model's ability of explaining the spatial structure of urban agglomerations. The improved gravity model is shown as follows:

$$
\operatorname{Link}_{i j}=\frac{X_{i j}}{X_{i j}+X_{j i}} \times \frac{K_{i} K_{j}}{D_{i j}^{2}}
$$

where Link $\rightarrow$ represents the strength of the connection between city $i$ and city $j$ and $K_{i}$ and $K_{j}$ are the central function strength indexes of cities $I$ and $j$, respectively. $X_{i j}$ and $X_{j i}$ represent the tendency in population flow from city $i$ to city $j$ and from city $j$ to city $i$, respectively. $D_{i j}$ is the comprehensive distance between roads and railways in cities $i$ and $j$. In the same way, Link $\underset{j i}{ }$ can be obtained.

2.3.2. Social Network Analysis. Complex social systems can be abstractly represented by social networks, which generally consist of two elements: nodes and connections. Nodes can represent abstract members in the system, are the initiators 
of behaviors, and are the basic elements in social networks. Connections can represent various relationships such as affiliation, direction, and connection between two nodes in a social network and are a representation of the behavior between nodes [59]. The social network analysis method uses a quantitative analysis of various network characteristic indicators, such as weighted degree, overall network density, and community exploration, to reveal the relationship between nodes and the characteristics of the entire network. In recent years, this method has also been widely used by scholars to study the spatial structure of urban agglomerations [32]. UCINET and Gephi are commonly used social network analysis software; this paper uses UCINET to calculate the network density and Gephi to calculate weighted degrees and community structures. The calculations of network polycentricity and link symmetry can be found in [3] and [60], respectively.

\section{Results}

3.1. Hierarchical Structure of Cities. The uneven distribution of intercity connections has led to the emergence of urban hierarchical structures. The city level is the basic factor used to distinguish the types of city network structures. The city levels in the urban agglomerations are divided and their scales compared as the basic premise for understanding the city network structure of the urban agglomerations. This paper uses the Jenks method to classify the BTHUA and the YRDUA (as shown in Tables 2 and 3).

Most high-grade cities in the BTHUA are located along the railway or high-speed rail lines or on the main traffic line, with developed traffic and superior geographical locations. Most low-level cities are located on the fringes of urban agglomerations and their economies are less driven by the "network radiation center" cities.

For the YRDUA, most high-level cities are along the Yangtze River or coastal hinterland. Most low-level cities are economically weak or have a poor geographical location, which hinders their connection with "network radiation center" cities.

In general, intercity connections are unevenly distributed within the urban agglomeration; cities have the characteristics of a hierarchical structure but are not isolated and can connect with other cities through nearby higher-level cities. In addition, the YRDUA far exceeds the BTHUA in the scale of its urban hierarchical connections, which reflects the large gap between the development of the BTHUA and that of the YRDUA.

In terms of weighted degree, the urban weighted degree has a large range, showing a serious imbalance. The top four cities (Beijing, Langfang, Tianjin, and Tangshan) in the BTHUA accounted for $83 \%$ of the total weight of the urban agglomeration, while the top four cities (Shanghai, Suzhou, Changzhou, and Nanjing) in the YRDUA accounted for $81 \%$ of the total weighted degree of urban agglomerations, reflecting the "eighty-twenty law" of a Pareto distribution.
3.2. Network Density and Network Polycentricity. Table 4 shows the calculation results for the city network density and network polycentricity of the BTHUA and YRDUA.

The network density characterizes the closeness of the connections between the network members. The greater the network density value, the greater the influence of the network on the interaction and behavior of its members. A closely connected network can provide various social resources for its members. For urban agglomerations, the network density mainly reflects the density of the connections between the city nodes in the regional urban agglomeration. The larger the network density value, the more prominent the interactions between cities. Network multicentrality represents the balance of connections among members in the network. For urban agglomerations, network polycentricity mainly reflects the degree to which the development of each city in the regional urban agglomeration has achieved equilibrium. The greater the network polycentricity, the smaller the development gap between cities and the more balanced the development between cities.

The network densities of the BTHUA and the YRDUA are 0.6923 and 0.7446 , respectively. The network density is relatively high, indicating that the overall city network of the BTHUA and YRDUA is compact, the cities in the network are closely connected, they engage in more frequent economic contacts and exchange activities, and their network concentration and radiation ability are strong. The network density of the YRDUA is $7.55 \%$ higher than that of the BTHUA, indicating that the urban connections of the BTHUA need to be further improved. The network polycentricity measures of the BTHUA and the YRDUA are 0.5484 and 0.6699 , respectively, and thus their network polycentricity is low, indicating that both BTHUA and YRDUA have an unbalanced overall city network. Urban connections mainly occur in a few central cities. The network polycentricity of the YRDUA is $22.16 \%$ higher than that of the BTHUA, indicating that the YRDUA has more balanced development and that the development gap between cities in the YRDUA is small.

3.3. City Link. The weighted degree is an important indicator that characterizes the connection strength of members in the network [61]. The higher the weight of a member is, the closer that member is to the center of the network and the more the power it has. The weighted degree can be used to characterize the status of a city. It is generally believed that a high weighted degree not only is conducive to the agglomeration and diffusion of resources in a city but also can strengthen the city's control over resource circulation. Considering previous urban hierarchical structures, this paper uses the natural break point method to divide the city connection (weighted degree) into four levels [62]. The network analysis tools in ArcGIS are further used to extract the contact flows of 13 node cities in the BTHUA and 27 node urban agglomerations in the YRDUA with a 
TABLE 2: City links and network grades of cities in the BTHUA.

\begin{tabular}{lccc}
\hline Grade & City network characteristics & Weighted degree & Cities \\
\hline 1 & Network radiation center & $190664-906065$ & Beijing, Langfang, and Tianjin \\
2 & Advanced network node & $56960-190663$ & Tangshan, Xingtai, and Handan \\
3 & Intermediate network node & $13725-56959$ & Shijiazhuang, Cangzhou, and Baoding \\
4 & Primary network node & $2347-13724$ & Hengshui, Qinhuangdao, Zhangjiakou, and Chengde \\
\hline
\end{tabular}

TABLE 3: Urban link and network grades of cities in the YRDUA.

\begin{tabular}{lccc}
\hline Grade & City network characteristics & Weighted degree & Cities \\
\hline 1 & $\begin{array}{c}\text { Network radiation center } \\
\text { Advanced network node }\end{array}$ & $\begin{array}{c}5910646-14972218 \\
1342193-5910645\end{array}$ & $\begin{array}{c}\text { Shanghai, Suzhou } \\
\text { Changzhou }\end{array}$ \\
3 & Intermediate network node & $192079-1342192$ & $\begin{array}{c}\text { Nanjing, Hangzhou, Wuxi, and Shaoxing, } \\
\text { Zhenjiang, Jiaxing, Yangzhou, Taizhou, } \\
\text { and Ma'anshan }\end{array}$ \\
4 & Primary network node & $7452-192078$ & $\begin{array}{c}\text { Huzhou, Wuhu, Nantong, Ningbo, } \\
\text { Chuzhou, Hefei, Yancheng, Tongling, }\end{array}$ \\
& & Zhoushan, Wenzhou, Xuancheng, Taizhou, Jinhua, Chizhou, and Anqing
\end{tabular}

Note: Taizhou, which is a Grade 3 city, is located in Jiangsu Province, and Taizhou, which is a Grade 4 city, is located in Zhejiang Province.

TABle 4: Network density and polycentricity of the two major urban agglomerations in China.

\begin{tabular}{lcc}
\hline Urban agglomeration & Network density & The degree of network polycentricity \\
\hline BTHUA & 0.6923 & 0.5484 \\
YRDUA & 0.7446 & 0.6699 \\
\hline
\end{tabular}

connection degree greater than 0 and present them in geographic space in the form of a network flow graph (as shown in Figures 2 and 3).

For the BTHUA, the network spatial pattern of urban connections presents two characteristics. (1) The backbone network presents a triangular shape, referring to the triangular network formed by the four cities of Beijing, Langfang, Tianjin, and Tangshan. Among them, Beijing and Langfang have the closest urban connection, a first-level connection, which benefits from Langfang's unique geographical advantages and political opportunities. In recent years, Beijing has proposed defusing noncapital functions and expressed the need to transfer low-end industry. Langfang is adjacent to Beijing and belongs to Hebei Province. It meets the political needs for the coordinated development of the BTHUA and is engaged in the concentrated undertaking of Beijing's industrial transfer. The city is developing rapidly and is closely linked to Beijing. Beijing and Tianjin, as well as Tianjin and Tangshan, have relatively close second-level urban ties. In recent years, Tianjin's GDP statistics have been squeezed due to a lack of innovation motivation, difficulties in industrial transformation and upgrading, and weak economic development, which has led to a decline in its links with Beijing. Tangshan's GDP ranking has consistently been among the best among cities in Hebei Province, and it has close links with Beijing and Tianjin. Because the Xiong'an New District, a state-level new district in China comparable to Shanghai's
Pudong New District, has settled in Baoding, its future vigorous development is bound to greatly improve Baoding's urban status, and the backbone network of the BTHUA is expected to change from a "triangular" to a "quadrangular" shape consisting of four cities: Beijing, Baoding, Tianjin, and Tangshan. (2) The overall distribution of the network presents a trend of "sparse north and dense south," and the spatial distribution of urban connections is unbalanced. The city network in the area north of Beijing is sparse, and the urban connections between cities are at the fourth level. The urban connections among Zhangjiakou, Chengde, and Qinhuangdao are all below 50, and urban connections are extremely rare. Although Zhangjiakou and Chengde are adjacent to Beijing, they are not very effective because of Beijing's radiation, and there is no close connection between the three cities. Qinhuangdao is located in the northeast of the BTHUA region in a remote corner. It is far away from the capital Beijing and Shijiazhuang, the capital city of Hebei Province, and thus has less contact with the regional center. The GDP of the above three cities is the lowest in Hebei Province, and the urban economy is underdeveloped, which is the main reason for the sparse connection between the three. The cities in south of Beijing have a dense network of connections, with distributed second, third, and fourth levels of connections. The degree of connection between each city is above 1,000 . These cities have a large population, and most of them are located on the main railway and high-speed railway transportation lines. 


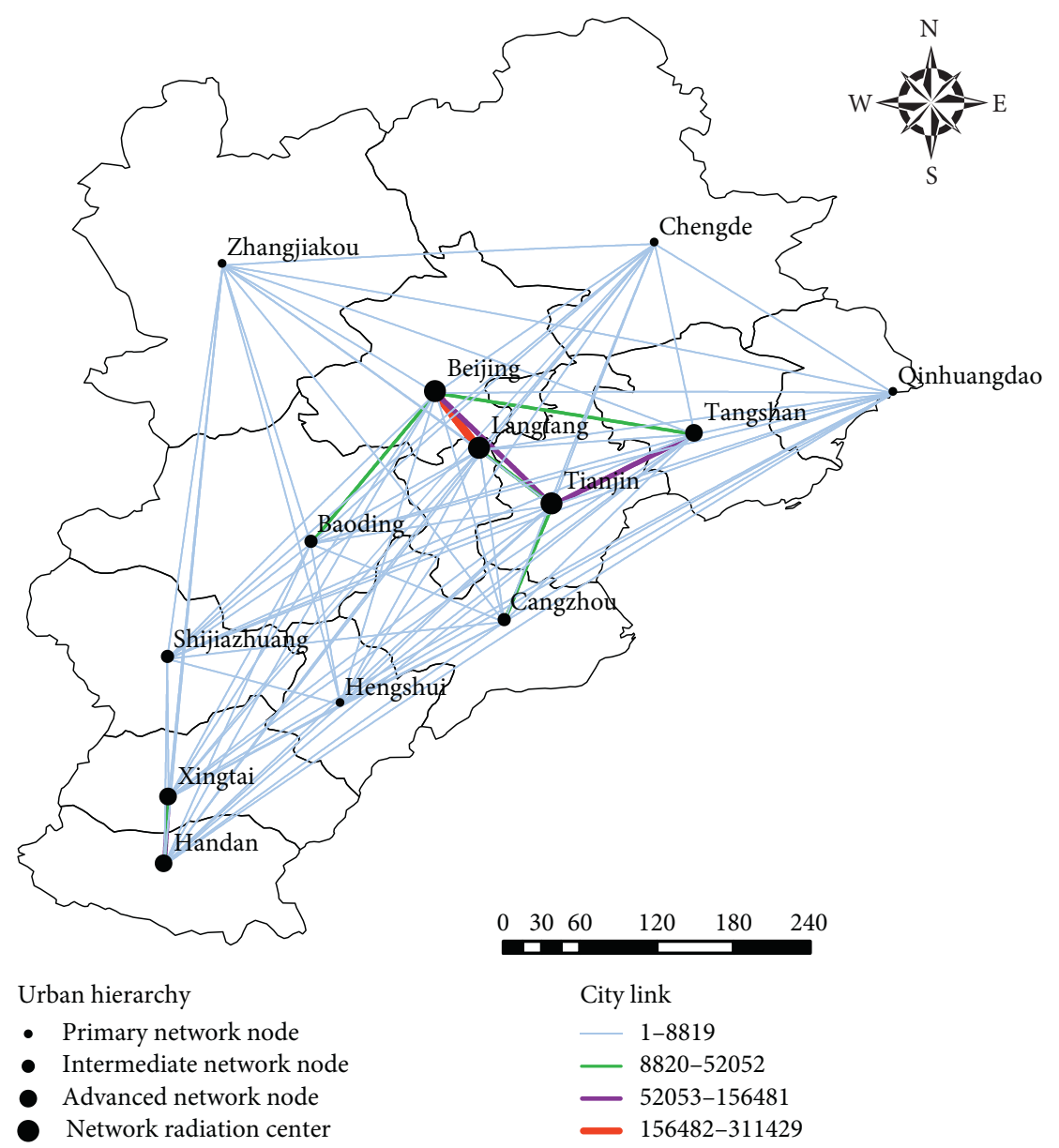

FIgURE 2: Macrospatial pattern of the city network in the BTHUA.

Transportation is developed, the economic, cultural, and social ties between cities are close, and urban ties are frequent.

For the YRDUA, the network spatial pattern of urban connections presents the following two characteristics. (1) The backbone network presents multiple "axes," referring to the 7 "axes" of Shanghai-Suzhou, Shanghai-Changzhou, Suzhou-Wuxi, Nanjing-Zhenjiang, Nanjing-Maanshan, Yangzhou-Taizhou, and Hangzhou-Shaoxing. According to point-axis theory, the concentrated social and economic facilities on the "axis" impose economic spillovers and innovation diffusion effects on the surrounding areas through information flow, technology flow, human flow, and financial flow and have strong economic attractiveness to nearby areas, creating cohesion. Among them, ShanghaiSuzhou and Shanghai-Changzhou are two "axes" representing first-level links that benefit from Shanghai's radiating and leading role in surrounding cities. Shanghai is China's financial, trade, and technological innovation center. Its complete infrastructure, developed public service systems, and a strong innovation atmosphere, on the one hand, continue to attract an inflow of innovative talent from surrounding cities; on the other hand, the outflow of venture capital and innovation resources has promoted knowledge spillovers between Shanghai and surrounding cities. Resource integration has improved the centrality of surrounding cities. The other five "axes" are connected with Suzhou, Nanjing, and Hangzhou as the centers, and they are all second-level connections. (2) The overall distribution of the network presents a trend of "dense north and sparse south," and the spatial distribution of urban connections is relatively balanced. The regional city network to the north of Hangzhou is close, and most of the urban connections between cities are measured as more than 10,000. The 6 "axes" of Shanghai-Suzhou, ShanghaiChangzhou, Suzhou-Wuxi, Nanjing-Zhenjiang, NanjingMaanshan, and Yangzhou-Taizhou are distributed in the northern part of the city network. The area south of Hangzhou has only one "axis" between Hangzhou and Shaoxing. Jinhua, Wenzhou, Taizhou, Zhoushan, and other cities have few connections, and most of the intercity connections measure below 1,000 . On the one hand, these cities rank relatively low in GDP, and they have insufficient economic attractiveness. On the other hand, southern cities are far from core node cities such as Shanghai, Nanjing, and Hangzhou and are less driven by the radiation of central cities.

In general, in the city connection network, each node city has a clear radiation range limit. The higher the level of the node city, the larger its radiation range. From the perspective 


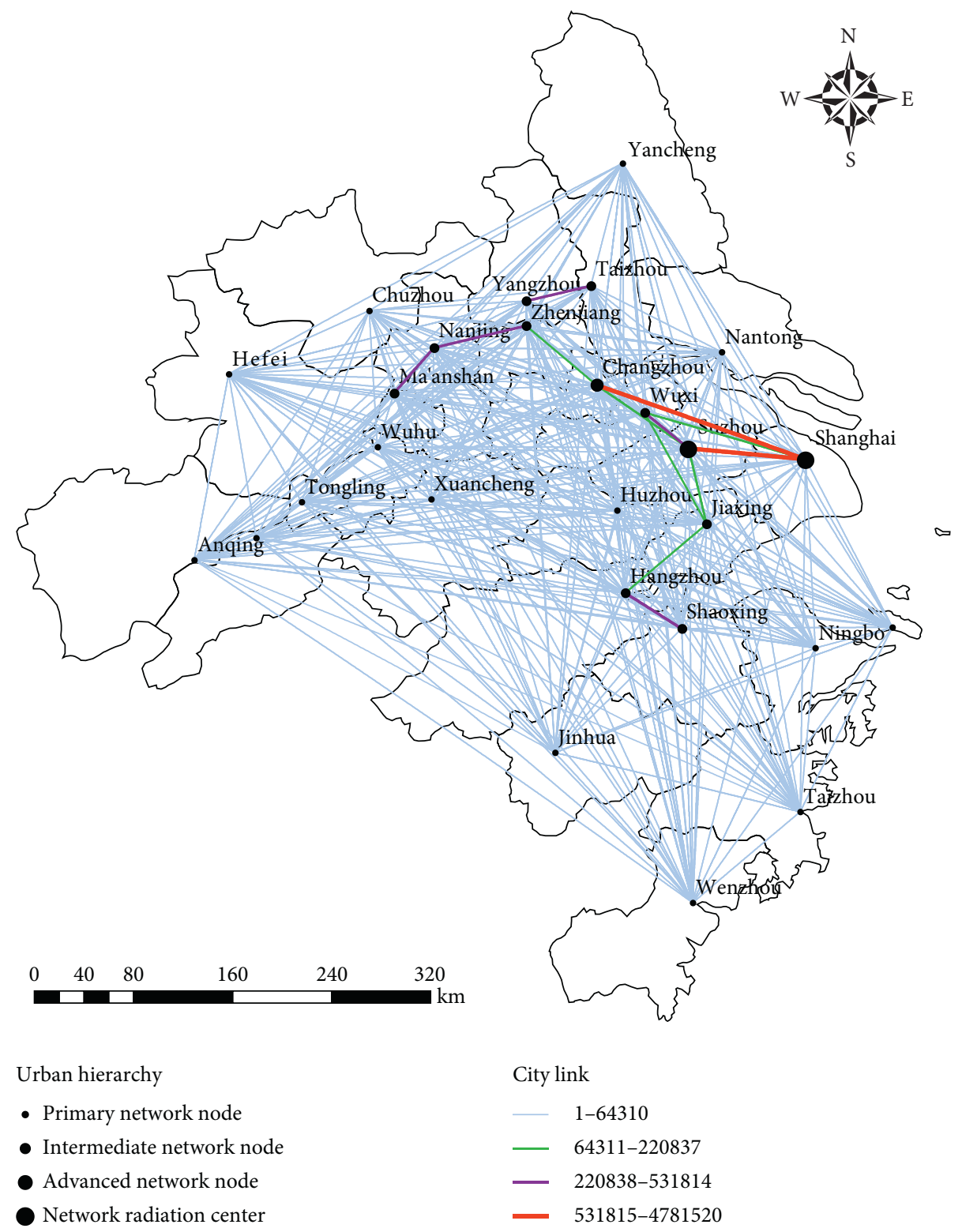

FIGURE 3: Macrospatial pattern of city network in the YRDUA.

of important connections, Beijing, the central city of the BTHUA network, and Shanghai, the central city of the YRDUA network, have the largest radiation range, basically covering the entire urban agglomeration. In the urban agglomeration network, there is a certain positive correlation between the level of the city nodes and the average connection distance. Spatial distance is still an important constraint on city connections. Edge cities always tend to establish connections with core cities first.

3.4. Link Symmetry. The interaction between members in a network is usually represented by symmetry. For urban agglomerations, symmetry, as a dimension in the city network, plays an important role in representing the decline in the level of the city system [63]. Link symmetry is used to measure the direction and degree of differences in urban links and can reflect the unequal flow of intercity elements and urban interactions. This paper uses link symmetry and population mobility tendency to describe the symmetry of China's two urban agglomeration networks. Based on [64], according to the classification principle of small differences within groups and large differences between groups, the link symmetry value is divided into three levels. A link symmetry of less than 0.2 indicates negligible asymmetry in the intercity links, between 0.2 and 0.3 is somewhat significant, between 0.3 and 0.5 is more significant, and greater than 0.5 is strongly significant, indicating that there are a strong unequal attraction and attention between cities. Figures 4 and 5 show the link symmetry of the intercity links between the BTHUA and the YRDUA, respectively.

For the BTHUA, the cities with significant intercity link symmetry in the city network include Xingtai to Chengde, 


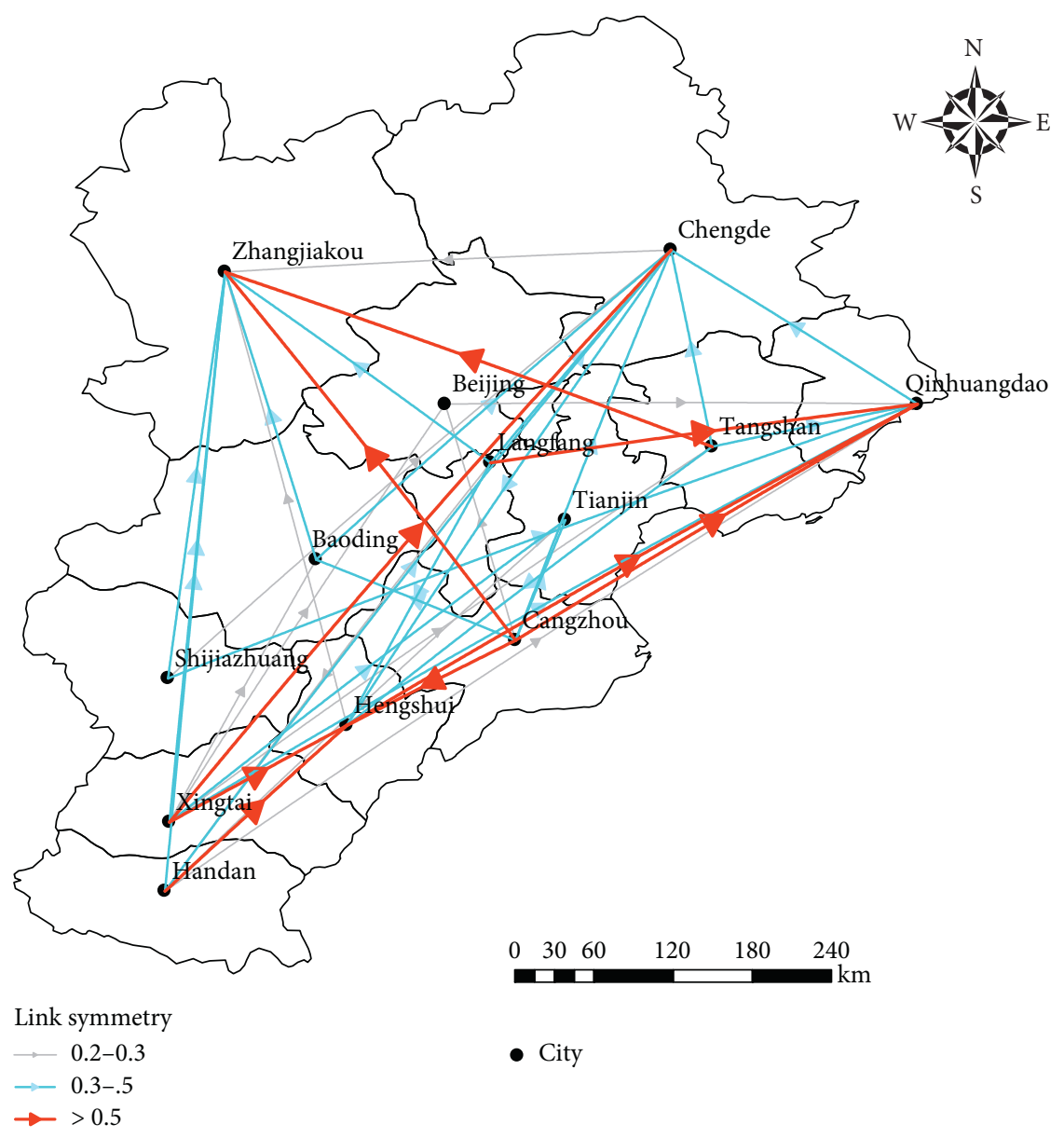

FIGURE 4: Link symmetry of the city network in the BTHUA.

Cangzhou to Zhangjiakou, Handan to Hengshui, Cangzhou to Qinhuangdao, Tangshan to Zhangjiakou, Hengshui to Qinhuangdao, Xingtai to Hengshui, Cangzhou to Hengshui, and Langfang to Qinhuangdao. From the perspective of the flow direction, the starting cities of these city pairs are cities with weak urban linkage centers (e.g., Beijing and Tianjin, which have strong urban linkage centers, are not starting cities). The destination cities of the city pairs, Qinhuangdao, Zhangjiakou, and Chengde, are all well-known tourist cities with high popularity. Although Hengshui is not a famous tourist city, Hengshui Middle School is almost a household name in China, so Hengshui also attracts more attention. The starting cities such as Handan and Cangzhou are economically and culturally relatively weak, while the destination cities are tourist destinations, with strong urban attractiveness, serving as a center of attention, which ultimately leads to very significant symmetry in these intercity links, expressed as an "attract and be attracted" relationship.

The YRDUA has more city pairs in the city network with significant intercity link symmetry, from Jinhua to Anqing, Taizhou to Anqing, Xuancheng to Zhoushan, Jinhua to Xuancheng, Taizhou to Yangzhou, Shaoxing to Yangzhou, Hangzhou to Zhoushan, etc. From the perspective of the flow direction, some of the destination cities of these city pairs are well-known cultural tourism cities. For example, Anqing is a national historical and cultural city known as the "state of culture" and "land of drama" and is the birthplace of Huangmei Opera. Xuancheng is the hometown of the Four Treasures of Chinese Scholars and a national historical and cultural city. Yangzhou is a world heritage city, world food capital, world canal capital, and a famous scenic tourist city. The other destination cities do not have significant urban characteristics; in general, they are basically the main cities of the YRDUA, and there is no centralized distribution of the destination cities. To a certain extent, this also shows that the symmetry in the intercity links of the YRDUA city clusters is only characterized by asymmetry in the individual intercity links and there is no asymmetry in the global intercity links.

In general, the symmetry of links represents the extent to which a city gives attention to and receives attention from the outside world, and it reveals relationships of unequal attraction between cities. The destination cities are generally those with more developed tourism industries (such as Qinhuangdao and Zhangjiakou in the BTHUA and Anqing and Yangzhou in the YRDUA) or larger cities. The starting cities are generally cities with poor comprehensive strength 


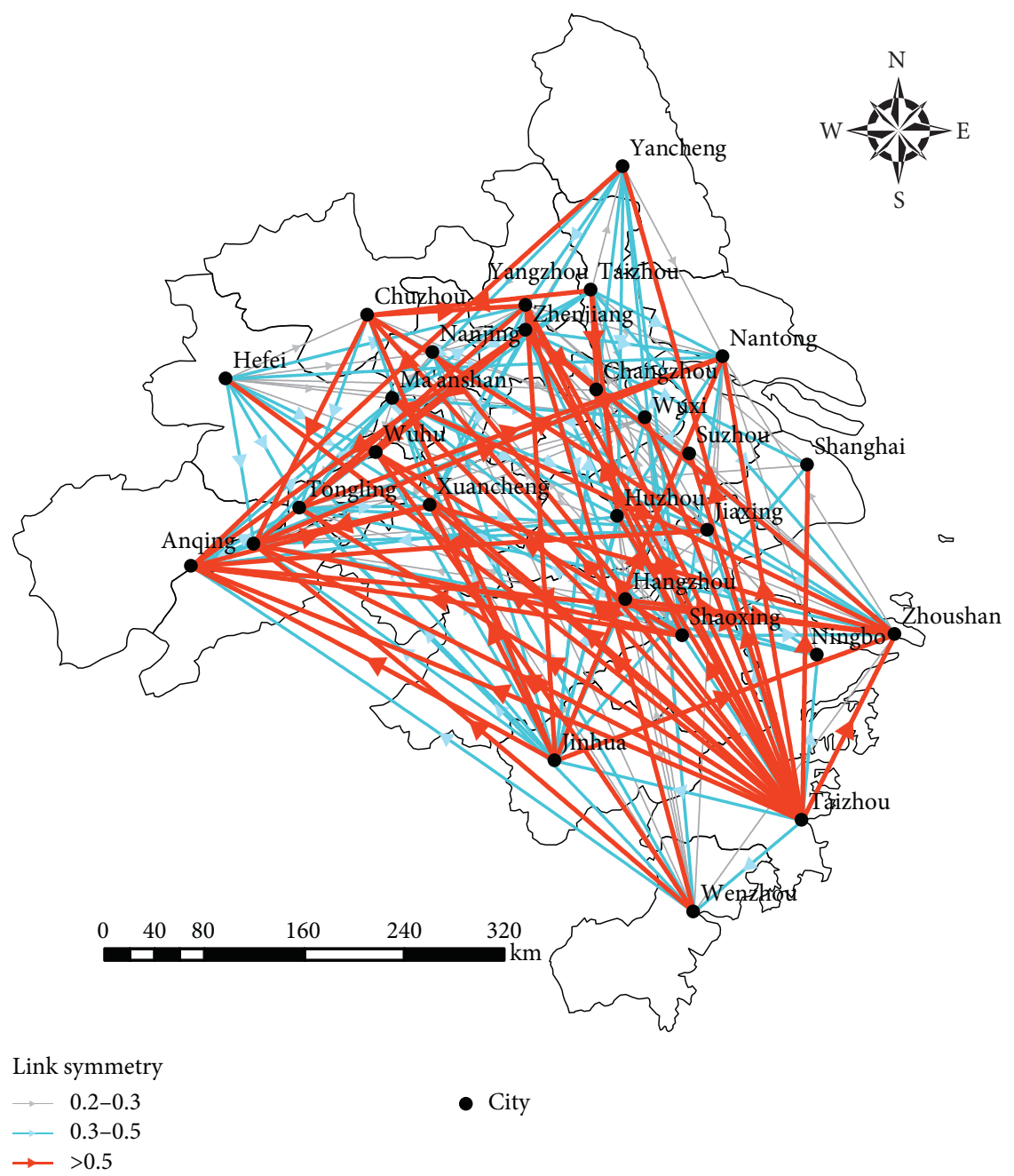

FIGURE 5: Link symmetry of the city network in the YRDUA.

and weak connections. Such cities are more likely to be "captured," forming an "attract and be attracted" relationship.

3.5. Community Structures. Community structure can be used to characterize the spatial organization mode of urban agglomerations, and this index reflects the relative intensity of intercity interaction. The community structure is an essential reflection of the mesoscale network [2], and it is also an important way to discover the network structure and function of the entire urban agglomeration. Identifying these communities is essential for discovering unknown functional modules, such as topics in information networks or urban groups in urban agglomerations. Due to the frequent economic, cultural, and technological exchanges between cities, it is easy to form a diverse collection of close internal connections. The intimacy of network members in the community is higher than that of members outside the community. Different community structures affect the geospatial organization of cities. Figures 6 and 7 show the community division of the BTHUA network and the YRDUA network, respectively.
For the BTHUA, the city network is divided into three communities, namely, community 1 , community 2 , and community 3. Community 1 is composed of 4 cities: Tianjin, Tangshan, Qinhuangdao, and Cangzhou. The above four cities all surround Bohai Bay of China, so community 1 can also be called the Bohai Rim City Community. The above four cities are all port cities, with frequent sea transportation and port trade between them, and the cities are closely connected. Community 2 consists of four cities: Shijiazhuang, Hengshui, Xingtai, and Handan. These four cities are all located in the central and southern Hebei functional expansion zone in the Urban Spatial Structure Plan of Hebei Province Urban System Planning (2016-2030). The community highlights the "axis + cluster" spatial organization model, promotes the formation of dense urban belts and industrial clusters along the transportation line, and creates a strategic hinterland for the coordinated development of Beijing, Tianjin, and Hebei and an important demonstration area for the coordinated development of urban and rural areas. Community 3 consists of 5 cities: Beijing, Langfang, Baoding, Zhangjiakou, and Chengde. Community 3 is the core functional area and ecological conservation area around Beijing and Tianjin. It plays a necessary role in undertaking 


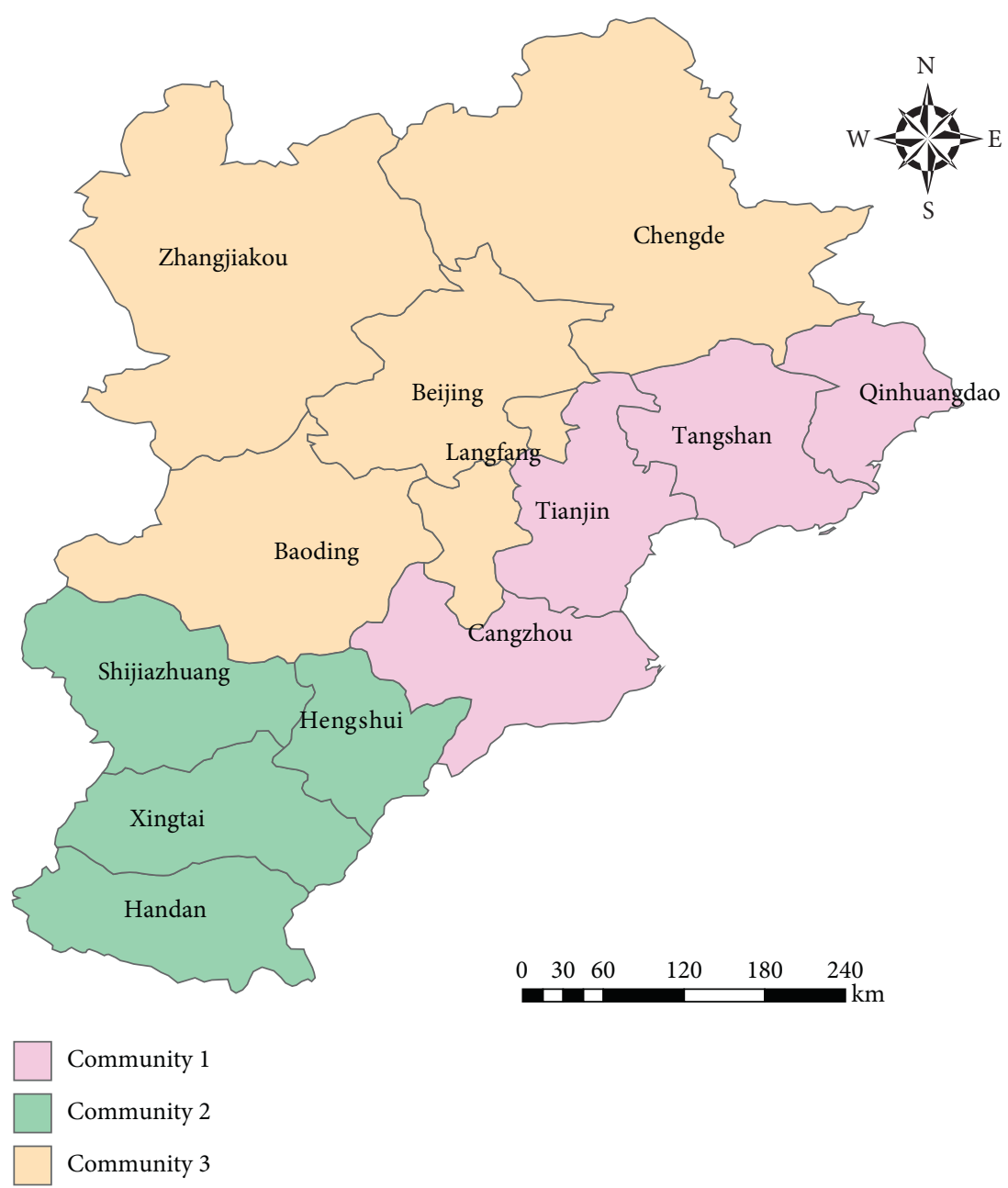

FIgURE 6: Community structures of the city network in the BTHUA.

the deconstruction of Beijing's noncapital functions, the transfer of various industries such as education, manufacturing, health, and elderly care, and accepting some tertiary industries such as regional logistics bases and vegetable and food materials wholesale markets [65]. Community 3 is a transformation base and a platform for undertaking specific functions. In addition, it is necessary to build a pattern of ecological towns and a green industrial system to create an ecological security barrier for the BTHUA.

For the YRDUA, the city network is also divided into 3 communities, namely, community 1 , community 2 , and community 3. Community 1 is composed of 14 cities: Nanjing, Nantong, Yancheng, Yangzhou, Zhenjiang, Taizhou, Hefei, Wuhu, Maanshan, Tongling, Anqing, Chuzhou, Chizhou, and Xuancheng. Community 1 has the most cities among the three communities of the YRDUA, indicating that these cities are closely connected. The community is centered on Nanjing and Hefei and covers two provinces, Jiangsu Province and Anhui Province. Nanjing and Hefei are the science and technology education centers of community 1 and have a sound modern industrial system. Other cities are dominated by characteristic industries and supporting industries such as modern agriculture, cultural tourism, health, and medicine and also serve as the production, processing, and supply base for agricultural products in the Yangtze River Delta. Community 2 consists of 5 citiesShanghai, Suzhou, Wuxi, Changzhou, and Jiaxing - and is centered on Shanghai. Although the community covers the fewest cities, it is the only community covering 3 provincial administrative regions, showing that Shanghai's urban radiation capacity exceeds the constraints of the administrative regions. Shanghai focuses on urban functions such as $R \& D$, design, high-end manufacturing, firm headquarters, and international trade and vigorously works to develop an innovative economy, service economy, and green economy. It is an industrial innovation center with global competitiveness. Cities such as Suzhou and Wuxi are driven by Shanghai and serve as expansion areas for Shanghai for supporting and noncore functions. Community 3 is composed of 8 cities: Hangzhou, Ningbo, Huzhou, Shaoxing, Wenzhou, Jinhua, Zhoushan, and Taizhou. Community 3 is centered on Hangzhou, and although it ranks second in the number of cities it covers, all of the cities are in Zhejiang Province, showing that Hangzhou's urban radiation capacity needs to be further improved. Except for Ningbo, which is a 


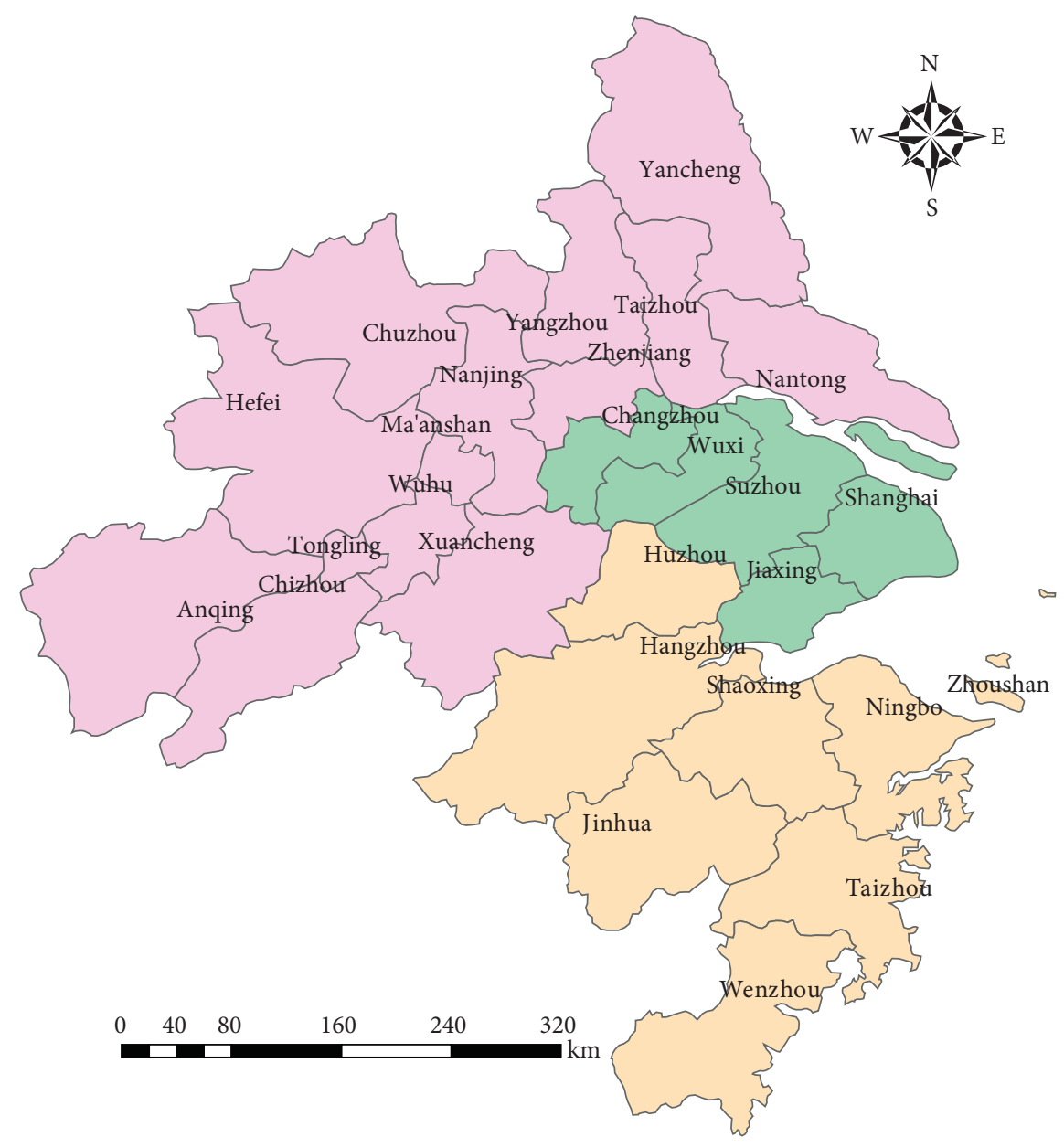

Community 1

Community 2

Community 3

FIgURE 7: Community structures of the city network in the YRDUA.

port and trading city, most of the cities are cultural and tourist cities and serve as green ecological barrier areas in the Yangtze River Delta.

In general, from a geographical perspective, most of the communities are composed of spatially continuous units, which indicates that the urban connections within urban agglomerations follow the law of distance attenuation. Considering the composition of the community members, most communities include cities with different provincial administrative units (such as community 1 and community 3 in the BTHUA and community 1 and community 2 in the YRDUA). Urban linkage overcomes the barriers of administrative boundaries and realizes the partial integration of urban agglomeration development.

\section{Conclusions and Discussion}

4.1. Conclusions. In previous studies on city networks based on gravity models, directionality has always been easily overlooked. The constructed urban connection network is often an undirected weighted network, but this does not mean that the directionality in the city network is not important. In contrast, the directionality in the city network is an important feature, as it portrays the asymmetry of interaction and connection between cities. In addition, the city network is diverse and integrated, which is a reflection of urban economic, social, environmental, and other factors. However, most previous studies have studied city networks from the perspectives of enterprises, organizations, social interactions, population flows, and transportation, but they do not reflect the panorama of city networks. Therefore, this paper uses online data such as the Baidu Index and traditional data such as statistical yearbooks to construct a model that includes population mobility and the strength of urban center functions. On this basis, a directional gravity model is established to provide a new perspective for studying city networks. Based on the improved gravity model, a city network connection matrix is constructed for the two major urban agglomerations in China, social network analysis methods are used to analyze the characteristics and structure 
of the city network space of the BTHUA and YRDUA, and the following main conclusions are drawn:

(1) From the perspective of hierarchical structure, the weighted degree of cities has a large range and is manifested as a serious imbalance that conforms to Pareto's law of distribution. Urban connections have obvious hierarchies. The YRDUA is far larger than the BTHUA in terms of the scale of its urban hierarchical connections.

(2) From the perspective of network density and network polycentricity, the overall city networks of the BTHUA and YRDUA are compact, with close connections between cities and strong network agglomeration and radiation capabilities. However, the low polycentricity of the network indicates that the overall city networks of the two urban agglomerations are not balanced and the urban connections mainly occur in a few central cities. The network density and network polycentricity of the YRDUA are $7.55 \%$ and $22.16 \%$, respectively, which is higher than those of the BTHUA and thus indicates that the YRDUA has more balanced urban development and closer connections between cities.

(3) From the perspective of city links, each node city in the BTHUA and YRDUA has a clear radiation range limit wherein the higher the city level, the larger the radiation range. Spatial distance is still an important constraint on urban connections, and fringe cities always tend to first establish connections with surrounding core cities. There is no phenomenon in which cities are isolated. Each city can connect with other cities through nearby higher-level cities. The backbone network of the BTHUA presents a triangular shape, the overall distribution of the network presents a trend of "sparse north and dense south," and the spatial distribution of the urban connections is unbalanced. The backbone network of the YRDUA presents multiple distributed axes, the overall distribution of the network presents a trend of "dense north and sparse south," and the spatial distribution of urban connections is relatively balanced.

(4) From the perspective of link symmetry, destination cities are generally tourist cities or larger cities. The starting cities are generally cities with poor comprehensive strength. Therefore, starting cities are more likely to be captured, forming an attract and be attracted relationship. In the BTHUA, the cities with significant symmetry in their intercity links are Xingtai to Chengde, Cangzhou to Zhangiiakou, and so on. In the YRDUA, there is only asymmetry in individual intercity connections, and there is no asymmetry in the global intercity connections.

(5) From the perspective of community structure analysis, most communities in the BTHUA and YRDUA are composed of spatially continuous units (i.e., cities), and urban connections follow the law of distance attenuation. The urban connections within the community overcome the barriers of administrative boundaries and realize the partial integration of the development of urban agglomerations. The BTHUA and the YRDUA have each formed 3 communities.

4.2. Research Limitations and Future Concerns. It is unavoidable that some shortcomings remain in this study. (1) The city network is a complex system, and the flow of people, logistics, capital, information, and technology among different cities are interdependent and interactive. Due to the limitations of research data, although the population mobility tendency model based on the Baidu Index can to a certain extent characterize the directionality of intercity links, there is still a large gap in the directionality of intercity links in reality. (2) Only cross-sectional data are used to conduct static research on the city network space of the two major urban agglomerations in China, and there remains a lack of research dynamically describing the evolution of urban agglomeration city networks from the two dimensions of time and space. (3) Although the characteristics and spatial pattern of the urban agglomeration network space are analyzed, the mechanisms forming and driving the urban agglomeration network space structure need to be clarified.

In the next work, we will further carry out a multispatial scale study of city and county units, use panel data with a long time span to analyze the characteristics and evolutionary laws of city network space in China's two major urban agglomerations, and adopt a quantitative model for spatial measurement to provide an in-depth discussion on the mechanism driving network evolution.

\section{Data Availability}

The primary data used to support the findings of this study have been explained clearly in Section 2.2.

\section{Conflicts of Interest}

The authors declare no conflicts of interest.

\section{Acknowledgments}

This study has been supported by the National Social Science Foundation of China (Grant no. 18ZDA044).

\section{References}

[1] X. Liu and M. Wang, "How polycentric is urban China and why? A case study of 318 cities," Landscape and Urban Planning, vol. 151, pp. 10-20, 2016.

[2] Z. Feng, H. Cai, and W. Zhou, "Structural characteristics and spatial patterns of the technology transfer network in the Guangdong-Hong Kong-Macao greater Bay area," Sustainability, vol. 12, no. 6, p. 2204, 2020.

[3] M. Zhao, Y. Zhong, and G. Xu, "Polycentric progress of the three major city regions in China, 2001-2009," Economic Geography, vol. 35, no. 3, pp. 52-59, 2015.

[4] W. Ke, W. Chen, and Z. Yu, "Uncovering spatial structures of regional city networks from expressway traffic flow data: a 
case study from Jiangsu Province, China," Sustainability, vol. 9, no. 9, p. 1541, 2017.

[5] M. Castells, "Grassrooting the space of flows," Urban Geography, vol. 20, no. 4, pp. 294-302, 1999.

[6] R. P. Camagni, From City Hierarchy to City Network: Reflections about an Emerging Paradigm, Springer, Berlin, Germany, 1993.

[7] B. Derudder and F. Witlox, "An appraisal of the use of airline data in assessing the world city network: a research note on data," Urban Studies, vol. 42, no. 13, pp. 2371-2388, 2005.

[8] M. C. Burns, J. Roca Cladera, and M. Moix Bergadà, "The spatial implications of the functional proximity deriving from air passenger flows between European metropolitan urban regions," GeoJournal, vol. 71, no. 1, pp. 37-52, 2008.

[9] H.-S. Lee, "The networkability of cities in the international air passenger flows 1992-2004," Journal of Transport Geography, vol. 17, no. 3, pp. 166-175, 2009.

[10] J. Jiao, J. Wang, and F. Jin, "Impacts of high-speed rail lines on the city network in China," Journal of Transport Geography, vol. 60, pp. 257-266, 2017.

[11] M. Diao, "Does growth follow the rail? The potential impact of high-speed rail on the economic geography of China," Transportation Research Part A: Policy and Practice, vol. 113, pp. 279-290, 2018.

[12] J. Zhou, L. Yang, and L. Li, "The implications of high-speed rail for Chinese cities: connectivity and accessibility," Transportation Research Part A: Policy and Practice, vol. 116, pp. 308-326, 2018.

[13] Y. Xianwu, W. Chuntao, L. Cailu, and W. Ping, "Spatial interaction and network structure evolvement of cities in term of China's railway passenger flow in 1990s," Progress in Geography, vol. 24, no. 2, pp. 80-89, 2005.

[14] H. Yang, F. Dobruszkes, J. Wang, M. Dijst, and P. Witte, "Comparing China's urban systems in high-speed railway and airline networks," Journal of Transport Geography, vol. 68, pp. 233-244, 2018.

[15] F. Bruinsma and P. Rietveld, "Urban agglomerations in European infrastructure networks," Urban Studies, vol. 30, no. 6, pp. 919-934, 1993.

[16] P. J. Taylor, "Leading world cities: empirical evaluations of urban nodes in multiple networks," Urban Studies, vol. 42, no. 9, pp. 1593-1608, 2005.

[17] B. Derudder, P. J. Taylor, M. Hoyler et al., "Measurement and interpretation of connectivity of Chinese cities in world city network, 2010," Chinese Geographical Science, vol. 23, no. 3, pp. 261-273, 2013.

[18] P. J. Taylor, B. Derudder, J. Faulconbridge, M. Hoyler, and P. Ni, "Advanced producer service firms as strategic networks, global cities as strategic places," Economic Geography, vol. 90, no. 3, pp. 267-291, 2014.

[19] P. Taylor, B. Derudder, M. Hoyler, P. Ni, and F. Witlox, "Citydyad analyses of China's integration into the world city network," Urban Studies, vol. 51, no. 5, pp. 868-882, 2014.

[20] M. Zhao, X. Liu, B. Derudder, Y. Zhong, and W. Shen, "Mapping producer services networks in mainland Chinese cities," Urban Studies, vol. 52, no. 16, pp. 3018-3034, 2015.

[21] F. Pan, Z. He, T. Sigler, K. Martinus, and B. Derudder, "How Chinese financial centers integrate into global financial center networks: an empirical study based on overseas expansion of Chinese financial service firms," Chinese Geographical Science, vol. 28, no. 2, pp. 217-230, 2018.

[22] F. Pan, W. Bi, J. Lenzer, and S. Zhao, "Mapping urban networks through inter-firm service relationships: the case of China," Urban Studies, vol. 54, no. 16, pp. 3639-3654, 2017.
[23] F. Pan, S. X. B. Zhao, and D. Wójcik, "The rise of venture capital centres in China: a spatial and network analysis," Geoforum, vol. 75, pp. 148-158, 2016.

[24] S. D. Brunn and M. Dodge, "Mapping the "worlds" of the World Wide Web," American Behavioral Scientist, vol. 44, no. 10, pp. 1717-1739, 2001.

[25] Q. Wang and M. Zhao, "Research on the city network of Guangdong, Hongkong and Macao from the perspective of information flow: analysis based on baidu index," Journal of Regional and City Planning, vol. 29, no. 3, pp. 281-293, 2018.

[26] C. Deng, X. Song, B. Xie, M. Li, and X. Zhong, "City network link analysis of urban agglomeration in the middle Yangtze River basin based on the Baidu Post Bar data," Geographical Research, vol. 37, no. 6, pp. 1181-1192, 2018.

[27] Z. Feng, W. Bo, and C. Yingxue, "Research on China's city network based on users' friend relationships in online social networks: a case study of Sina Weibo," GeoJournal, vol. 81, no. 6, pp. 937-946, 2016.

[28] G. Pflieger and C. Rozenblat, Introduction. Urban Networks and Network Theory: The City as the Connector of Multiple Networks, SAGE Publications Sage UK, London, UK, 2010.

[29] C. Fang, Q. Sheng, and S. Li, "Economic links between the cities in north Anhui based on gravity model," Areal Research \& Development, vol. 37, no. 2, pp. 25-28+35, 2018.

[30] Z. Yao, J. Tu, H. Niu, H. A. Lin, and J. Li, "The research on urban agglomeration spatial structure of Cheng-Yu economic zone," Economic Geography, vol. 37, no. 1, pp. 82-89, 2017.

[31] X. Guan and L. Liu, "Spatial connection of Beijing-TianjinHebei urban agglomerations based on modified gravity model," Urban Problems, vol. 11, no. 11, pp. 21-26, 2014.

[32] P. Zhang, Y. Zhao, X. Zhu, Z. Cai, J. Xu, and S. Shi, "Spatial structure of urban agglomeration under the impact of highspeed railway construction: based on the social network analysis," Sustainable Cities and Society, vol. 62, Article ID 102404, 2020.

[33] J. Zhao, L. Zhang, and J. Song, "Spatial structure of urban system and its evolution in Jing-Jin-Ji urban agglomeration," Areal Research and Development, vol. 37, no. 2, pp. 9-13, 2018.

[34] J. Yu and J. Ma, "Spatial pattern evolution of economic links in Shandong peninsula urban agglomeration," Scientia Geographica Sinica, vol. 38, no. 11, pp. 1875-1882, 2018.

[35] Y. Fan, S. D. Zhang, Z. Y. He et al., "Spatial pattern and evolution of urban system based on gravity model and whole network analysis in the huaihe river basin of China," Discrete Dynamics in Nature and Society, vol. 2018, Article ID 3698071, 11 pages, 2018.

[36] H. Jiang, Y. Lu, and G. Lv, "A study on foreign economic contact of important central cities in Jiangsu and Zhejiang provinces and the city of Shanghai," Progress in Geography, vol. 6, no. 6, pp. 82-89, 2008.

[37] C. Zeng, Y. Song, D. Cai et al., "Exploration on the spatial spillover effect of infrastructure network on urbanization: a case study in Wuhan urban agglomeration," Sustainable Cities and Society, vol. 47, Article ID 101476, 2019.

[38] F. Wang, X. Wei, J. Liu, L. He, and M. Gao, "Impact of highspeed rail on population mobility and urbanisation: a case study on Yangtze River Delta urban agglomeration, China," Transportation Research Part A: Policy and Practice, vol. 127, pp. 99-114, 2019.

[39] Z. Wang, L. Liang, Z. Sun, and X. Wang, "Spatiotemporal differentiation and the factors influencing urbanization and ecological environment synergistic effects within the BeijingTianjin-Hebei urban agglomeration," Journal of Environmental Management, vol. 243, pp. 227-239, 2019. 
[40] J. Zhang and W. Yang, "The measurement and analysis of the quality of economic growth of Beijing, Shanghai, Guangzhou and Shenzhen," Journal of Industrial Technological Economics, vol. 35, no. 3, pp. 143-151, 2016.

[41] P. Zhao, D. Lyu, H. Hu et al., "Population-development oriented comprehensive modern transport system in China," Acta Geographica Sinica, vol. 75, no. 12, pp. 2699-2715, 2020.

[42] J. Newig, "Public attention, political action: the example of environmental regulation," Rationality and Society, vol. 16, no. 2, pp. 149-190, 2004.

[43] C. P. Scheitle, "Google's insights for search: a note evaluating the use of search engine data in social research," Social Science Quarterly, vol. 92, no. 1, pp. 285-295, 2011.

[44] X. Lu, "Construction of public environmental awareness index based on web search behaviors," Environmental Ence \& Management, vol. 42, no. 6, pp. 26-29, 2017.

[45] Z. M. T. G. Z. Yan, “The impact of users' cognition and emotion on exploratory web search behavior: an experimental study," Information and Documentation Services, vol. 39, no. 3, pp. 80-87, 2018.

[46] Y. Sun and B. Lv, "A review of researches on the correlation between Internet search and economic behavior," Management Review, vol. 23, no. 7, pp. 72-77, 2011.

[47] X. Yang, B. Pan, J. A. Evans, and B. Lv, "Forecasting Chinese tourist volume with search engine data," Tourism Management, vol. 46, pp. 386-397, 2015.

[48] M. Wang, Y. Kuang, and N. Huang, "Spatial characteristics of intercity population flow propensity in the pearl River Delta region: based on the Spatio-temporal change of Internet attention index," Tropical Geography, vol. 37, no. 1, pp. 33-42, 2017.

[49] X. Huang, L. Zhang, and Y. Ding, "Study on the predictive and relationship between tourist attractions and the baidu index: a case study of the forbidden city," Tourism Tribune, vol. 28, no. 11, pp. 93-100, 2013.

[50] E. S. Lee, “A theory of migration," Demography, vol. 3, no. 1, pp. 47-57, 1966.

[51] T. Xu and Y. Yao, "Urban population migration and housing price fluctuation:an empirical research based on the Census data and baidu migration data," Journal of Jiangxi University of Finance \& Economics, vol. 1, no. 1, pp. 11-19, 2018.

[52] L. Jiahui, "Housing prices, public goods and the willingness of floating populations to Stay in the city," Journal of Finance and Economics, vol. 45, no. 6, pp. 86-100, 2019.

[53] H. Li, C. Duan, and Y. Bai, "A study on Chinese migrant's city-residing willingness and its influencing factors," Population Journal, vol. 41, no. 1, pp. 80-88, 2019.

[54] C. Y. Wang and W. U. Lao-Er, "Emigration,Megalopolis and real estate price-—a study for the perspective of spatial econometrics," Population \& Economics, vol. 4, no. 4, pp. 63-67+58, 2007.

[55] T. Lu, "Least effort law in network information retrieval behaviors," Chinese Journal of Medical Library \& Information Science, vol. 19, no. 11, pp. 53-55+58, 2010.

[56] Q. Wang, Y. Liu, X. Li, B. Zhang, and C. Zhang, "Evolution characteristics of 24 major cities' network attention degree of six elements of tourism in China," World Regional Studies, vol. 26, no. 1, pp. 45-55, 2017.

[57] W. Ruan, S. Zhang, Y. Li, and X. Zheng, "Spatiotemporal differentiation and influencing factors of Chinese's tourism demand to Thailand," Tourism Tribune, vol. 34, no. 5, pp. 76-89, 2019.
[58] M. Qin and H. Liu, "Baidu Index,Mixed-frequency model and Sanya tourism demand," Tourism Tribune, vol. 34, no. 10, pp. 116-126, 2019.

[59] D. Song and W. Qi, "The social network in the evolution of regional economic integration of northeast China," Jilin University Journal Social Sciences Edition, vol. 58, no. 4, pp. 97-107+206, 2018.

[60] L. Zheng, W. Shifu, Z. Miaoxi, and W. Kang, "Exploratory analysis of directed weighted network of city," Geographical Research, vol. 32, no. 7, pp. 1253-1268, 2013.

[61] Y. Sun, S. Yao, and L. Zhang, "Spatial expansion of urban network for the three coastal agglomerations of China: a study based on integrated traffic information network," Science Geographical Sin, vol. 38, pp. 827-837, 2018.

[62] C. Liu, C. Niu, and J. Han, "Spatial dynamics of intercity technology transfer networks in China's three urban agglomerations: a patent transaction perspective," Sustainability, vol. 11, no. 6, p. 1647, 2019.

[63] N. Limtanakool, T. Schwanen, and M. Dijst, "Developments in the Dutch urban system on the basis of flows," Regional Studies, vol. 43, no. 2, pp. 179-196, 2009.

[64] Y. Ma, F. Xue, W. Sun, and M. Li, "Analysis of urban network structure of the economic zone on the West Coast of the Taiwan Strait: a study through the lens of functional networks and innovation cooperation networks," Geographical Research, vol. 38, no. 12, pp. 3010-3024, 2019.

[65] G. Zhang and K. Wen, Innovation Ecosystem: Theory and Practice, Economy \& Management Publishing House, Beijing, China, 2018. 